\title{
Molecular characterization of mutations causing $\beta$-thalassemia in Faisalabad Pakistan using the amplification refractory mutation system (ARMS-PCR)
}

\author{
S. M. Baig, F. Rabbi, U. Hameed, J. A. Qureshi, Z. Mahmood, S.H. Bokhari, A. Kiani, H, Hassan, J.M. Baig, \\ A. Azhar, T. Zaman \\ Health Biotechnology Division, National Institute for Biotechnology \& Genetic Engineering (NIBGE), Faisalabad Pakistan
}

BACKGROUND: Faisalabad is the third biggest city of Pakistan. Majority of the population is Punjabi while other ethnic groups are in minority.

AIMS: The present study was undertaken to find the mutations causing $\beta$-thalassemia in Faisalabad Pakistan.

MATERIALS AND METHODS: A total of $285 \beta$-globin alleles from 143 unrelated families having at least one transfusion-dependent child were analyzed by using amplification refractory mutation system (ARMS-PCR). RESULTS: FSC-8/9 $(+G)$ and IVS-I-5 $(G \rightarrow C)$ were the most common mutations. The allele frequency for FSC-8/9 $(+G)$ was $38.59 \%$ while frequency for IVS-I-5 $(\mathrm{G} \rightarrow \mathrm{C})$ was $37.89 \%$. The high frequency $(76.48 \%)$ of IVS-I-5 $(G \rightarrow C)$ and FSC-8/9 $(+\mathrm{G})$ on various alleles provides a strong evidence of intermarriages.

CONCLUSIONS: By using ARMS-PCR, the mutations were successfully characterized in $95.79 \%$ of subjects, while $4.21 \%$ remain to be characterized. This study will facilitate the implementations of genetic counseling and prenatal diagnosis in the population of Faisalabad.

Key Words: ARMS-PCR; $\beta$-thalassemia; mutations detection; Faisalabad; mutations; Pakistan.

Thalassemia is a single gene disorder of hemoglobin $(\mathrm{Hb})$, characterized by the deficient or abolished synthesis of one or more of the globin chains of $\mathrm{Hb}$. $\beta$ Thalassemia is one of the major monogenic single gene disorders in the world population and it was the first disease studied by using the techniques of molecular biology. Indian subcontinent and South-East Asia have the highest prevalence of $\beta$-thalassemia and comprise the so-called 'thalassemia belt." ${ }^{[1],[2]}$ At molecular level, $\beta$-thalassemia represents a great heterogeneity as more than 380 mutations have been identified for the $\beta$-globin gene responsible for this disease (OMIM, 2005). The frequency and spectrum of these mutations vary among different populations. Immigration plays a major role in both the distribution and the extent of mutation variations within each country. ${ }^{[3]} \beta$-Thalassemia is one of the most common genetic disorders in Pakistan. The carrier rate in different regions of Pakistan varies from 1.4 to $8.0 \%$ with an average of $5.0 \% .{ }^{[4]}$ In order to control $\beta$-thalassemia, a comprehensive study dealing with molecular diagnosis of mutation causing this disease is needed for carrier detection and establishment of prenatal diagnostic program. ${ }^{[5]}$ Preventive programs for $\beta$-thalassemia consisting of genetic counseling, carrier detection, and prenatal diagnostic are the effective approaches. ${ }^{[6]}$ The introduction of chorionic villus sampling (CVS) along with polymerase chain reaction- (PCR) based technique has made the prenatal diagnosis rapid and reliable at early stage of pregnancy ${ }^{[6]}$ These mutations can be detected by amplification refractory mutation system (ARMS). However, for characterization of rare mutations of $\beta$-thalassemia gene sequencing and single strand conformation polymorphism techniques are reliable tools. ${ }^{[7]}$

\section{Materials and methods}

A total of 285 alleles from 143 unrelated families, were analyzed for $17 \beta$-globin gene mutations reported in Pakistan. These subjects were identified at Health Biotechnology Division NIBGE, Faisalabad with collaboration of Ali Zaib Blood Transfusion Center, 
Chiniot blood bank and Allied Hospital, Faisalabad.

\section{DNA extraction}

Blood samples (5-10 $\mathrm{ml}$ ) from 143 families having at least one transfusion-dependent child with thalassemia major/intermedia were collected in vacutainer with EDTA as anticoagulant and kept at $-20^{\circ} \mathrm{C}$ until DNA extraction. The DNA from leukocytes was extracted by $\mathrm{NaCl}$ method. ${ }^{[8]}$ While isolation of DNA from CVS was done following the protocol of Jackson et al. ${ }^{[9]}$

The isolated DNA was dissolved in 0.5-1 $\mathrm{ml}$ TE buffer (20 mM Tris pH 8.0, $1 \mathrm{mM}$ EDTA). The isolated DNA was evaluated by agarose gel electrophoresis after staining with ethidium bromide and exposure to UV light. Impure DNA samples were re-extracted with phenol/ chloroform method.

\section{Characterization of mutations by ARMS-PCR}

ARMS-PCR allows the characterization of point mutations directly by the presence or absence of amplification using allele specific primers. For the diagnosis of specific point mutation a pair of allelespecific primers one of which has its 3 ' terminal nucleotide complementary to the point mutation (Mt ARMS primer) and other to the normal DNA sequence (N ARMS primer) was used. ${ }^{[10],[11]}$ Each DNA sample was screened for the 17 most common mutations reported in Pakistan. The samples uncharacterized for 17 most common mutations will be sequenced. The ARMS analysis was performed in a reaction mixture of $20 \mu$ containing 1 X PCR buffer, 50 pmoles of each of four primers, $0.5-1 \mu \mathrm{g}$ of genomic DNA, $0.25 \mathrm{mM}$ of dNTPs, $1.5 \mathrm{mM} \mathrm{MgCl}_{2}$, and $0.5-1 \mathrm{U}$ of Taq polymerase. The thermal cycling consisted of 33 cycles of denaturation at $94^{\circ} \mathrm{C}$ for $45 \mathrm{~s}$ and primer annealing and extension at $67^{\circ} \mathrm{C}$ for $1.5 \mathrm{~min}$. In the final cycle, the extension was prolonged for $6 \mathrm{~min}$. After amplification the entire product was mixed with $1 \mathrm{X}$ loading dye and electrophoresed on a $1.8 \%$ agarose gel containing ethidium bromide for 20-60 min at $100 \mathrm{~V}$, visualized and photographed under UV light.
Results

In this study, a total of $285 \beta$-globin alleles from 143 unrelated families having at least one transfusiondependent child were analyzed. By using rapid DNA analytical techniques like, PCR and ARMS-PCR we have characterized $273(95.79 \%)$ alleles out of 285 for 17 mutations, i.e., FSC-8/9 (+G), IVS-I-5 (G $\rightarrow$ C), Cd 41/42 (-CTTT), 619 bp del, IVS-II-1 $(G \rightarrow A)$, IVS-II-848 $(C \rightarrow A)$, IVS-I-I $(G \rightarrow T)$, IVS-I-1 $(G \rightarrow A), C d 15(G \rightarrow$ A), Cd $16(-C), C d 26(G \rightarrow A), C d 30(G \rightarrow C), C d 30$ $(G \rightarrow A), C d 39(C \rightarrow T),-88(C \rightarrow T), C a p+1(A \rightarrow C)$ and Initiation $\mathrm{Cd}(\mathrm{T} \rightarrow \mathrm{C})$. The percentage prevalence of these mutations shows that FSC-8-9 $(+G)$ is the predominant mutation (38.59\%) while the second common mutation in these chromosomes is IVS-I-5 (G $\rightarrow$ C) with prevalence of $37.89 \%$ and third common mutation is the Cd $41 / 42$ (-CTTT) (9.12\%). The $619 \mathrm{bp}$ deletion at the $3^{\prime}$ end of the b-gene is common and even that is restricted to India and Pakistan, where it accounts for approximately one third of the $\beta$-thalassemia alleles. ${ }^{[12],[13]}$ Deletion mutation, $619 \mathrm{bp}$, was found only in $3.15 \%$ chromosomes in this study.

The pattern of $\beta$-thalassemia mutations in Faisalabad is given in [Table 1]. In this study, two prenatal diagnoses were carried out by using CVS at 12-13 weeks. The ARMS-PCR method was used for prenatal diagnosis of $\beta$-thalassemia mutations in families at risk. The mutations had already been characterized in our screening program prior to receipt of fetal sample for families at risk. Results were delivered in 1-3 days. In prenatal diagnoses, one fetus was heterozygous (carrier/ trait) and pregnancy was continued. While the other

Table 1: Frequency of $\beta$-thalassemia mutations in Faisalabad

\begin{tabular}{l|c|c}
\hline Mutations & Alleles & Frequency (\%) \\
\hline FSC-8/9 $(+\mathrm{G})$ & 110 & 38.59 \\
IVS-I-5 $(\mathrm{G} \rightarrow \mathrm{C})$ & 108 & 37.89 \\
CD-41/42 $(-\mathrm{CTTT})$ & 26 & 9.12 \\
619 bp del & 09 & 3.15 \\
IVS-II-848 $(\mathrm{C} \rightarrow \mathrm{A})$ & 05 & 1.75 \\
IVS-I-1 $(\mathrm{G} \rightarrow \mathrm{A})$ & 05 & 1.75 \\
IVS-II-1 $(\mathrm{G} \rightarrow \mathrm{A})$ & 04 & 1.40 \\
CD-15 $(\mathrm{G} \rightarrow \mathrm{A})$ & 03 & 1.0 \\
IVS-I-1 $(\mathrm{G} \rightarrow \mathrm{T})$ & 02 & 0.70 \\
Cap+1 $(\mathrm{A} \rightarrow \mathrm{C})$ & 01 & 0.35 \\
\hline Total & $\mathbf{2 7 3}$ & $\mathbf{9 5 . 7 9}$ \\
\hline
\end{tabular}


pregnancy was terminated in first trimester as fetus was diagnosed homozygote for parental mutations. In both cases the parents were first-degree cousins and carriers for the same mutation, i.e., IVS-I-5 $(G \rightarrow C)$ and 619 del.

\section{Discussion}

The information on distribution pattern of different $\beta$ thalassemia mutations in various populations is important for the establishment of comprehensive prenatal diagnosis programs based on DNA analysis. ARMS is fast and reliable method. In this study, 285 alleles were analyzed for $\beta$-thalassemia mutations in Faisalabad. FSC-8/9 $(+\mathrm{G})$ is diagnosed as the most common mutation in Faisalabad (38.59\%). However, our group and others have already reported this mutation with different frequency rates in various regions of Pakistan as $44 \%$ in North West Pakistan, $41 \%$ in Northern areas of Pakistan, $36 \%$ in Bahawalpur, and $4.5 \%$ in Karachi. ${ }^{[4],[14]}$

The second most common mutation is IVS-I-5 $(\mathrm{G} \rightarrow \mathrm{C})$ (37.89\%). High frequency of FSC-8/9 and IVS-I-5 mutations suggests that these may be the oldest $\beta$ thalassemia mutations in the Indian subcontinent. ${ }^{[7]}$ Though IVS-I-5 $(\mathrm{G} \rightarrow \mathrm{C})$ mutation is the most prevalent mutation of $\beta$-globin gene almost all over Pakistan and India, the overall distribution of mutations differs radically between different regions of the country. ${ }^{[4],[12],[14]}$

The third most common mutation in this region is CD41/42 (-CTTT) that constitutes about $9.12 \%$. In Pakistan, 20 mutations are reported but most of the mutations are less common or rare and frequency differs in different regions. ${ }^{[4]}$

In Faisalabad region, only ten mutations were detected: that is, FSC-8/9 $(+\mathrm{G})$, IVS-I-5 $(\mathrm{G} \rightarrow \mathrm{C}), \mathrm{Cd}$ 41/42 (-CTTT), 619 bp del, IVS-II-848 (C $\rightarrow$ A), IVSI-1 $(G \rightarrow A)$, IVS-II-1 $(G \rightarrow A)$, Cd $15(G \rightarrow A)$, IVS-I-1 $(G \rightarrow$ $T)$ and $C a p+1(A \rightarrow C)$. The present results are particularly from Faisalabad while previous data and reports from other groups working in Pakistan did not represent the mutations pattern in Faisalabad. ${ }^{[4],[14],[15]}$ By using 16 ARMS-PCR primer sets and a direct PCR method for the detection of 619 bp deletion mutation, we have characterized $95.79 \%$ of the alleles in this study. In a previous study by Bukhari[16] $40.08 \%$ true

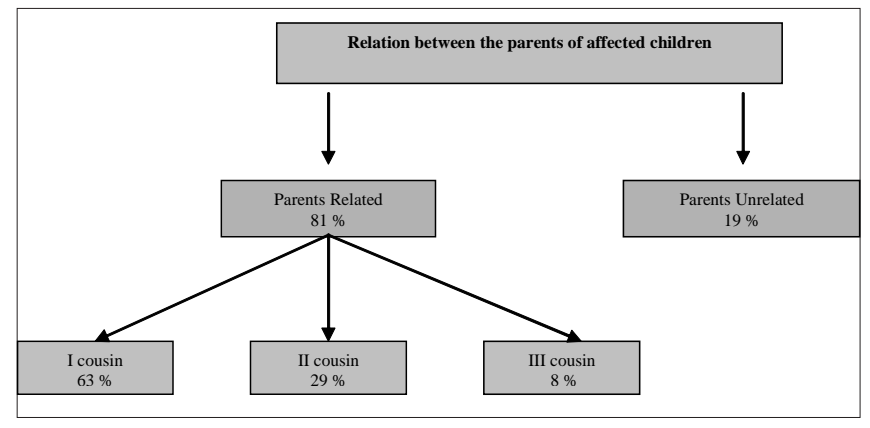

Figure 1: Relation between the parents of affected children

homozygotes children were reported. In this study $70 \%$ patients are found to be true homozygotes, i.e., having same genotype. The rate of first cousin marriages among the parents of affected children is $63 \%$. Total consanguinity rate including second cousin relationships and beyond is $81 \%$ while $19 \%$ are unrelated [Figure 1]. This data confirms the relationship of consanguinity and high rate of true homozygousity of mutations in population of Faisalabad. There are only few centers, which offer prenatal diagnosis of $\beta$-thalassemia in Pakistan. In the vicinity of Faisalabad, there is no facility of prenatal diagnosis. Therefore considering this matter of great importance, we established prenatal diagnosis services at NIBGE and offered prenatal diagnosis to couples at risk.

\section{Acknowledgment}

We are thankful to Doctors and staff of Ali Zaib Blood Transfusion Center, Allied Hospital/Punjab Medical College and Chiniot Blood Bank, Faisalabad for providing the blood samples of thalassemic children and their families.

\section{References}

1. Cao A, Luisella S, Galanello R, Rosatelli MC. Molecular diagnosis and carrier screening for $\beta$-thalassemia. JAMA 1997;278:1273-7.

2. Weatherall DJ, Clegg JB. The $\beta$-thalassemia syndromes. $4^{\text {th }}$ Edn. Oxford: Blackwell Scientific publication; 2001. p. 635-87.

3. Gupta A, Hattori Y, Agarwal S. Initiation codon mutation in an Asian Indian Family. Am J Hematol 2002;71:134-6.

4. Ahmed S, Saleem M, Sultana N, Raashid Y, Waqar A, Anwar $\mathrm{M}$, et al. Prenatal diagnosis of $\beta$-thalassemia in Pakistan: experience in a Muslim country. Prenat Diagn 2000;20:378-83.

5. Khan SN, Riazuddin S, Galanello R. Identification of three rare $\beta$-thalassemia mutations in Pakistan. Hemoglobin 2000;24:15-22.

6. Tuzmen S, Tadmouri GO, Ozer A, Baig SM, Ozcelik H, 
Basaran S, et al. Prenatal diagnosis of $\beta$-thalassemia and sickle cell anemia in Turkey. Prenat Diag 1996;16:252-8.

7. Agarwal S, Hattori Y, Agarwal SS. Rare beta $\beta$ thalassemia mutations in Asian Indians. Prenat Diagn 2000;20:986-91.

8. Miller M, Dykes DD, Poesky HF. A simple salting out procedure for extracting DNA from human nucleated cells. Nucl Acids Res 1988;16:215.

9. Jackson DP, Hayden JD, Quirke P. Extraction of nucleic acid from fresh and archival material. In PCR A Practical Approach, McPherson MJ, Quirke P, Taylor GR (eds). Oxford University Press: New York; 1991. p. 30-2.

10. Newton CR, Graham A, Heptinstall LE, Powell SJ, Summers C, Kalsheker N, et al. Analysis of any point mutation in DNA. The amplification refractory mutation system (ARMS). Nucl Acids Res 1989;17:2503-16.

11. Old JM, Varawalla NY, Weatherall DJ. Rapid detection and prenatal diagnosis of $\beta$-thalassemia: studies in Indian and Cypriot populations in the U.K. Lancet 1990;336:834-7.

12. Varawalla NY, Old JM, Sarker R, Venkatesan R,
Weatherall DJ. The spectrum of $\beta$-thalassemia mutations on the Indian subcontinent: the basis for prenatal diagnosis. Br J Hematol 1991;78:242-7.

13. Baysal E, Sharma S, Wong SC, Jogessar VB, Huisman $\mathrm{TH}$. Distribution of $\beta$-thalassemia mutations in three Asian Indian populations with distant geographic locations. Hemoglobin 1994;18:201-9.

14. Baig SM, Rabbi F, Yaqoob N, Baig S, Khan MM, Shamsi ST, et al. Molecular study and prenatal diagnosis of $\beta$ thalassemia in Pakistan by ARMS-PCR. First Scientific Symposium of The Children Hospital Lahore held on December 3-4. 1999.

15. Khan SN, Zafar AU, Riazuddin S. Molecular genetic diagnosis of $\beta$-thalassemia in Pakistan. J Pak Med Assoc 1995 ;45: 66-69.

16. Bukhari $\mathrm{SH}$. Molecular spectrum and characterization of $\beta$-thalassemia in Pakistan. M.Phil. Thesis, submitted to Quaid-i-Azam University, Islamabad, Pakistan. 1996.Pp: 57-59.

\title{
Expert comments
}

\author{
S. Fucharoen \\ Thalassemia Research Center, Institute of Science and Technology for Research and Development, Mahidol University, \\ Salaya Campus, Thailand
}

The article on 'Molecular characterization of mutations causing $\beta$-thalassemia in Faisalabad, Pakistan, using the amplification refractory mutation system (ARMS-PCR)' by Shahid Mahmood Baig described the molecular basis of $\beta$-thalassemia in certain part of Pakistan. Authors had found a unique common four mutations that accounted for almost $75 \%$ of the mutations among the 284 alleles of $\beta$ thalassemia genes. This is quite similar to the studies carried out in many countries that there seems to be a rather ethnic-specific thalassemia mutations in different populations. The authors decided to use allele-specific PCR for point mutation detection. This technique is simple and works quite well after the condition for individual mutations were established. However, authors have to be very careful in doing prenatal diagnosis using this technique alone. Because the interpretation of 'positive result' depends on the identification of the appropriated bands of DNA after electrophoresis. False 'negative results' may occur by various means such as human error (forget to put in the primers and other reagents in the reaction tube), deleterious primers/enzyme, etc.

The article by Gorakshakar et al. on 'detection of two rare $\beta$-thalassemia mutations $[-90(\mathrm{C} \rightarrow \mathrm{T})$ ] and CD $26(\mathrm{C} \rightarrow \mathrm{T})$ among Indians' reported two rare mutations in the Indian $\beta$-thalassemia patients. Since these two mutations are rare and not previously reported in India, the authors have to use many molecular techniques such as RDB, DGGE, and DNA sequencing to search for the mutations. All of these molecular techniques of point mutation detection have some advantages and disadvantages. However, as a reference center like this one in Mumbai, it is important to develop their expertise to serve the families. Question is for a small center with limited facilities and manpower, how can they identify these rare mutations? Thus, authors should plan further to develop simple technique such as RDB or ARMS to pick up these rare mutations in the population at large.

Address for Correspondence : S Fucharoen, Thalassemia Research Center, Institute of Science and Technology for Research and Development, Mahidol University, Salaya Campus, 25/25 M. 3, Puttamonthon 4 Rd., Puttamonthon, Nakornpathom 73170, Thailand, E-mail: grsfc@mahidol.ac.th 